\title{
Rituales, descentramientos territoriales y niveles de identidad: La Semana Santa Marinera de Valencia
}

\author{
Rituals, Territorial Decentration and Levels \\ of Identity: The Semana Santa Marinera \\ in Valencia
}

\author{
Pedro García Pilán \\ Departament de Sociologia i Antropologia Social. \\ Universitat de València
}

\section{RESUMEN}

El propósito del artículo es estudiar los procesos de recomposición identitaria y espacial que la modernidad globalizada opera sobre los rituales religiosos tradicionales, a partir del caso de la Semana Santa Marinera de Valencia (España). Frente a la visión del ritual como reproductor de una única identidad local, se constata cómo los niveles de identidad locales, sin desaparecer, se ven progresivamente solapados con nuevas territorialidades de base cada vez más incierta, que incluyen desde redes de procesiones basadas en el derecho canónico hasta encuentros de extensión estatal. Por fin, la proyección mediática del ritual supone la creación de nuevas comunidades virtuales y desterritorializadas, fenómeno cuya complejidad se incrementa con la creación de comunidades virtuales a través de Internet. El descentramiento espacial del ritual supone así la activación de nuevas formas de identidad, construidas de manera híbrida y transversal, y refuerza su proceso de secularización.

Palabras clave: Ritual, Identidad, Territorio, Descentramiento, Semana Santa Marinera, Procesiones.

\section{SUMMARY}

The aim of this paper is to study how the processes of spatial and identity recomposition brought about by a globalized world affect traditional religious rituals, with particular reference to the Semana Santa Marinera processions in Valencia (Spain). Instead of the ritual giving rise to a single local identity, it can be seen that levels of local identity —-while not disappearing — overlap more and more with increasingly vague new territorialities ranging from processional networks based on canon law to state-organized meetings. Media coverage of the ritual means that new virtual communities with 
no fixed territorial base are created, and the complexity of this phenomenon further increases with the creation of virtual online communities. The spatial decentration of ritual, therefore implies the creation of new forms of identity constructed along hybrid and crosssectional lines, thereby strengthening the process of secularization.

Key words: Ritual, Identity, Territory, Decentration, Seafaring Holy Week, Processions.

\section{INTRODUCCIÓN}

Hace ya bastante tiempo que Karl Mannheim llamaba la atención sobre la necesidad de profundizar en el estudio de "los contactos continuos en el espacio y en el tiempo como las bases de las tradiciones concurrentes e históricas" (1962: 134). Y aunque el maestro alemán no hiciese explícitamente de los fenómenos religiosos el objetivo principal de sus comentarios, no podemos olvidar que el binomio formado por tradición y territorio implica casi siempre la religión: ya en el siglo XIX, Fustel de Coulanges (1984) estableció la indisoluble relación que, en la Antigüedad, se daba entre ambos factores, inaugurando una línea interpretativa que encuentra uno de sus principales baluartes en Durkheim (1982: 409), y cuyos ecos continúan resonando en las investigaciones de numerosos antropólogos y sociólogos.

Ahora bien, en nuestra modernidad globalizada y cuando, a raíz de los importantes escritos de Beck (1998) y Giddens (1997), se discute acerca del suelo de posibilidad de la tradición en nuestras "destradicionalizadas" sociedades (Heelas, Lash y Morris 1996), este problema no se puede plantear en los mismos términos en que lo hicieran Mannheim o, de manera más sistemática, Shils (1975). Más bien, las condiciones de pluralización e hibridación cultural características de la modernidad globalizada permiten invertir tales propuestas pues, como se ha apuntado en otro lugar, "en muchas de las que llamamos 'tradiciones urbanas' lo más que se alcanza a vislumbrar es un mosaico, cruce o convivencia de tradiciones plurales mantenidas por segmentos diferenciados de población" (Cruces Vilallobos 2004: 21). Habría que añadir que, inmersos como estamos en pleno proceso de recomposición espacio-temporal cabe hablar de "otro tipo de territorio" (Ortiz 1996), donde las fronteras y los usos híbridos de los espacios, desde todas las escalas, se han problematizado hasta límites insospechados no hace mucho. En definitiva, cabe pensar que, si los espacios se problematizan, también lo harán las tradiciones ligadas a los mismos.

Por otra parte, no podemos olvidar que, en sociedades caracterizadas por una configuración simbólica descentrada y politeísta (Beriain 2000), tampoco el ritual puede ser ya leído en términos estrictamente durkheimianos, como muy bien ha señalado Gerd Baumann (1992). Y ello pese a que la 
necesidad de expresar una identidad colectiva diferenciada suele ser vista como un factor determinante para explicar la propia existencia del ritual festivo: desde la perspectiva de la eficacia del ritual como activador de identidades se ha podido explicar, por ejemplo, la revitalización de fiestas que parecían condenadas a su extinción por la lógica de la modernidad (Boissevain 1992; Jimeno Salvatierra 2002), prolongándose así una línea clásica de investigación que hacía de las fiestas tradicionales la más destilada exhibición de las identidades locales (Pitt-Rivers 1986).

Ahora bien, quedarnos exclusivamente en este nivel de interpretación significaría renunciar a comprender el carácter abierto del ritual en las actuales condiciones de modernidad avanzada o globalizada. Parece pues conveniente preguntarse si es posible ir más allá de los planteamientos expuestos. Sumamente interesante es, al respecto, la propuesta de Stuart Hall, quien postula, frente a cualquier esencialismo, un concepto estratégico y posicional de la identidad:

El concepto acepta que las identidades nunca se unifican y, en los tiempos de la modernidad tardía, están cada vez más fragmentadas y fracturadas; nunca son singulares, sino construidas de múltiples maneras a través de discursos, prácticas y posiciones diferentes, a menudo cruzados y antagónicos (Hall 2003: 17).

Todo ello nos obliga, pues, a repensar el vínculo entre ritual religioso y territorio local. La presente contribución intenta incidir en esta línea, abordando la creciente complejidad que el ritual produce y reproduce, desde el punto de vista de la identidad y del territorio asociado al mismo. Para ello, se analizará el caso del ritual festivo de la Semana Santa Marinera de Valencia. Se trata de una celebración vinculada a las cuatro parroquias de tres barrios del frente marítimo de la ciudad: El Cabanyal, El Canyamelar y El Grao, llamados también Poblados Marítimos de Valencia, que fueron pueblos independientes hasta finales del siglo XIX y que mantienen un fuerte sentimiento de identidad diferenciada hasta hoy día. En la actualidad, un total de treinta y dos cofradías se reparten entre estos tres barrios, articulando una fiesta que, en una ciudad cuyo referente festivo aparece claramente monopolizado por las omnipresentes y mediáticas Fallas (Ariño Villarroya 1992), puede ser vista a priori como un ejemplo de nicho de tradición local, meramente residual y fuertemente ligada a un territorio bien delimitado.

TERritorio y Niveles de SignificaCión IDENTITARIA EN LA SEMANA SANTA MARINERA DE VALENCIA

En un contexto de complejidad social creciente, donde aumenta la interacción entre agentes que se caracterizan más por su heterogeneidad que 
por su homogeneidad, la coparticipación en un mismo cuerpo de tradiciones supone necesariamente la consideración del ritual como un campo de negociación y resignificación permanente. Desde este punto de vista, resultan importantes aportaciones como las de Isidoro Moreno, que advirtió hace ya algún tiempo de que son varios los niveles de identidad que pueden reproducir los rituales colectivos de religiosidad popular, consideración que le llevaba a distinguir entre identidades "grupales", "semicomunales", "comunales" y "supracomunales" (Moreno Navarro 1990a; 1990b). Descartado aquí el segundo tipo —no nos enfrentamos a una comunidad dividida en "mitades", como es el caso del ya clásico estudio de Moreno sobre un pueblo del Aljarafe sevillano (Moreno Navarro 1972)—, me inspiraré inicialmente en esta clasificación para tratar de establecer los niveles de identidad presentes en la secuencia ritual desarrollada a lo largo de la celebración de la Semana Santa Marinera de Valencia. Es decir, se procederá a deslindar los distintos nosotros que interactúan dentro del nosotros que articula el principal nivel identitario del ritual. Se partirá, pues, de la propuesta de Moreno para intentar avanzar proponiendo otros niveles de identidad, suscitados en diferentes direcciones, a partir de las transformaciones recientes del sujeto celebrante del ritual y de los distintos niveles espaciales asociados al mismo.

\section{Niveles de identidad en el ritual de la Semana Santa Marinera de Valencia}

\section{Identidad subgrupal}

Cualquier cofradía cumple los requisitos establecidos por Merton para ser considerada un grupo de referencia: establece formas duraderas y moralmente consagradas de interacción social, permite la autodefinición y, finalmente, la definición como miembro del grupo por parte de los otros (internos y externos a éste) (Merton 1995: 92-160; 287-290). Sin embargo, una cofradía no es una entidad homogénea, sino que está compuesta por muy variados vínculos familiares y polimorfas redes de amigos. Todos los cofrades no hacen el mismo uso de ella: en la práctica, hay quienes mantienen vínculos continuos con la cofradía a lo largo de todo el año y quienes tan sólo acuden en Semana Santa, con todas las situaciones intermedias que puedan pensarse. Por eso, como espacio de sociabilidad densa para un núcleo de cofrades, se establecen a lo largo del año relaciones que se reafirman, entre diaria y semanalmente, en lo que podríamos llamar rituales de identidad subgrupal: se trataría de los que realizan los pequeños grupos que se reúnen regularmente en el local propio — cada cofradía dispone de uno- a programar la próxima fiesta, a poner al día papeles y cuentas o, simplemente, a cenar o tomar una cerveza. Estos pequeños rituales, ligados 
al estrechísimo y perfectamente delimitado territorio privado de la cofradía, pueden variar su amplitud, como sucede normalmente los fines de semana, cuando un mayor núcleo de cofrades acude a ejercer la sociabilidad, lo que no significa, ni mucho menos, la disolución de tales subgrupos (aunque sí la intensificación de las interacciones entre ellos). No se trata de un nivel de identidad muy importante a primera vista, pues se construye en un ámbito entre semipúblico (la cofradía como asociación abierta) y semiprivado (la intimidad de los grupos de amigos); sin embargo, estos rituales, difuminados a lo largo de todo el año, son fundamentales para que, llegados los días señalados (la Semana Santa), se produzca el estallido festivo. A partir de aquí, la intimidad de los amigos se pondrá en público; las redes informales ceden su protagonismo, según el momento, al grupo o a toda la comunidad celebrante.

\section{Identidad grupal}

En tanto que una cofradía es un grupo de referencia, entramos con éste en el primer nivel de identidad verdaderamente fundamental para entender el ritual. A diferencia del esbozado anteriormente, éste se construye y reproduce de manera pública, en un acto de teatralización a través del cual el grupo se brinda en espectáculo, demandando el reconocimiento externo. Bourdieu (2001: 77) señala cómo estos actos de teatralización constituyen "la forma elemental de objetivación" de los grupos, para sí mismos y para los demás. Así, podemos hablar de rituales de identidad grupal para referirnos a las pequeñas procesiones en las que, a lo largo de las celebraciones, cada cofradía sale a la calle ella sola, reafirmando su especificidad (es decir, su identidad colectiva más primaria), frente al resto de grupos básicos. Estas pequeñas procesiones, que transcurren siempre por el territorio de las respectivas demarcaciones parroquiales (pero sin cubrirlo nunca totalmente), actúan como "la exposición pública y externa de todos los elementos que giran alrededor de cada cofradía”, tal y como se ha afirmado para un caso observado en el ámbito andaluz (Checa 1992: 98-99). Se trata de rituales de cohesión del grupo, de división y de reafirmación frente al resto. Es, en definitiva, el nivel primario del nosotros frente al ellos. Y debe insistirse en que este ámbito de identidad se asienta sobre una base territorial nítidamente definida: cada cofradía es parte integrante de un barrio determinado.

\section{Identidad comunal}

Se incluyen en este nivel los actos que se aglutinan en torno a cada una de las parroquias que articulan la fiesta, como las procesiones de Domingo 
de Ramos y los Via Crucis de la mañana de Viernes Santo. Evidentemente, nos encontramos ante comunidades imaginadas, entre otras cosas porque se ha podido verificar que buena parte de los procesionantes vive ya fuera del territorio parroquial (García Pilán 2010: 184-187); sin embargo, el ritual sirve precisamente para reafirmar unos vínculos ideales con éste, con lo que la comunidad imaginada se convierte en expresa a través de la práctica del mismo. Cambian aquí los niveles de significación del ellos frente al nosotros: es la identidad de barrio la que aquí predomina (las parroquias se corresponden con barrios), materializada claramente en todos y cada uno de los estandartes que encabezan el paso de cada hermandad. A diferencia de lo que sucede en el nivel anterior, aquí los territorios de cada parroquia son recorridos prácticamente al completo.

\section{Identidad supracomunal}

Podría resultar en apariencia paradójico hablar de "identidad supracomunal" para referirnos a unos barrios de la periferia de una ciudad; sin embargo, dado que se trata de barrios que, precisamente mediante la puesta en marcha del ritual, actúan como poblaciones diferenciadas, resulta posible hacerlo, pues se trata de un nivel de significación que unifica el nosotros de las tres comunidades imaginadas, es decir, los tres barrios implicados, frente al ellos externo a los mismos. La supracomunidad que aquí puede distinguirse se expresa, se concreta y se reafirma mediante magnas procesiones que abarcan los tres barrios y visitan las parroquias que oficialmente articulan la celebración: la Visita a los Monumentos del Jueves Santo, el Santo Entierro del Viernes Santo y el Desfile de Resurrección del Domingo de Pascua. Se trata, especialmente en los dos últimos casos, y oficialmente, de los actos estelares de la fiesta; a través de ellos se trascienden las microidentidades de base y los tres barrios, que en un pasado todavía no muy lejano fueron municipios independientes, se unifican frente al exterior; un exterior cuya percepción viene en gran medida capitalizada por la ciudad de Valencia. No significa esto que, en tales desfiles, las rivalidades entre los grupos primarios y comunales queden superadas; en realidad las identidades particulares pueden pugnar a la vez entre sí (en tanto que cofradías o grupos) y complementarse (en torno al barrio respectivo a la que cada una de ellas pertenece); así, al tiempo que pugnan por acercarse a sí mismas, afirman la identidad general, de forma que ésta, paradójicamente, se nutre y alimenta de distintos niveles de particularismos y atomizaciones.

Es decir, que de las rivalidades microidentitarias pasamos gradual y dialécticamente a una identidad colectiva, más o menos fragmentada, pero no por ello menos efectiva. En realidad, podría pensarse que asistimos a 
procesos de fisión y fusión similares a los descritos por Evans-Pritchard para la estructura segmentada de la estructura política nuer, en la que cada segmento se ve a sí mismo como una unidad independiente, pero a la vez puede ver a otro segmento como una unidad en relación a otra sección, de manera que fisión y fusión son dos aspectos del mismo principio segmentario (Evans-Pritchard 1992: 166-167). En todo caso, en este nivel, más que en ningún otro, es cuando la Semana Santa Marinera actúa y es expresamente calificada como las fiestas del pueblo, calificación que los actores dan frecuentemente al ritual.

En sus distintos registros, pues, las representaciones acerca de la fiesta propugnan la existencia de una comunidad distinta, que se diferencia de su entorno por hacer unas fiestas específicas. Hasta aquí, pues, nada que nos permita disentir del modelo interpretativo de Pitt-Rivers (1986): las fiestas actúan como "epifanías de las identidades" locales, como afirma acertadamente Homobono (2004). Sin embargo, la ambigüedad del ritual como campo productor de significados dista de terminar aquí. En condiciones de modernidad, el ritual festivo es casi siempre polivalente y los significados que despliega pueden en ocasiones resultar abiertamente contradictorios, al menos en apariencia, pues sería erróneo considerar únicamente a la Semana Santa Marinera como el ritual de afirmación de tres barrios que, rememorando cíclicamente su pasado histórico, se vuelven a hermanar ritualmente una vez al año. Por el contrario, puede darse, y de hecho se da, la aparente paradoja de que, paralelamente, la misma ciudad de Valencia se apropie de la fiesta: como ha expresado un alto cargo político de la ciudad, nos encontramos ante la segunda fiesta de la ciudad ${ }^{1}$. Aunque se trata todavía de un estado relativamente incipiente, no podemos pasarlo por alto, pues tiende a configurarse como el discurso más recurrente de los políticos y de los medios de comunicación, y poco a poco va calando entre los propios cofrades y los asistentes a los espectáculos procesionales. Emerge así una nueva retórica, cargada de nuevos tópicos: valga como ejemplo la opinión del presidente de la Diputación de Valencia, expresada en 1997, para quien "la Setmana Santa Marinera és representació viva del sentir artístic i pietós del poble valencià"2.

A la creación de este emergente ámbito de identidad contribuye en buena medida la condición parásita que, según Gonzalo Abril (1997: 302) adquieren determinadas prácticas políticas, al hacerse los medios de comunicación eco de las actividades de los políticos que, durante toda la Semana Santa,

${ }^{1}$ Levante-EMV, 27-III-1999, suplemento "Semana Santa", p. 12.

2 Semana Santa Marinera de Valencia. Libro oficial 1997. Valencia: Junta Mayor de la Semana Santa Marinera, 1997, p. 8. 
rondan por los barrios del Distrito Marítimo de Valencia, no sólo en los grandes acontecimientos, sino también visitando las sedes de las cofradías por las noches. No es de extrañar, pues, la frecuencia con que se puede ver a altos cargos de la administración local cargar con las imágenes más emblemáticas de la fiesta (que una persona cargue con la imagen de un crucificado es uno de los rasgos más distintivos de la celebración), es decir, las que mayor cantidad de seguidores arrastran. Quizás sea excesiva la tipología elaborada al respecto por Manuel Delgado, quien sitúa a los políticos entre los "rapinyaires festius" que proliferan en propio provecho en torno a los rituales festivos (Delgado 1992: 115-135), pero, en todo caso, sí se produce, en determinados momentos, una evidente transferencia del carisma, que se desliza de la imagen sacra a la celebridad que se apropia de ella. Los medios de comunicación contribuyen así a esa manufactura del carisma, de la que Salvador Giner ha hablado con acierto y profusión (2003: 147-178).

La verificación de tal fenómeno podría sugerirnos una antropología de la dominación simbólica, que parecería responder al modelo gramsciano de hegemonía. Sin embargo, tal visión unidireccional resultaría, como mínimo, insuficiente. En realidad, es la propia organización de la fiesta la que, en su nivel más alto (la Junta Mayor de la Semana Santa Marinera ${ }^{3}$ ) o desde su base (las distintas cofradías), contribuye a alimentar esta espiral, al demandar constantemente la presencia de altos cargos de la política, la atención de los medios de comunicación, o al reivindicar el carácter patrimonial y festivo de la fiesta (García Pilán 2002). El sujeto celebrante de la misma, el nosotros, puede perder bastante definición a partir de esta perspectiva desde el punto de vista territorial, pero adquiere el reconocimiento externo que, en condiciones de modernidad, garantiza la construcción de una identidad fuerte.

Así pues, asistiríamos a la paradoja de que la ciudad concede la organización de su segunda fiesta a unos barrios de la periferia. Paradoja sólo aparente: la desidentificación local ha sido señalada por Gil Calvo (1996) como una de las inevitables tendencias de la transformación festiva de la modernidad. Es posible que la terminología de este autor, expresada en términos estrictamente negativos, no sea la más adecuada, y que el término reterritorialización sirva para explicar mejor los hechos descritos. En todo caso, el propio ritual ya ha sancionado el cambio: las procesiones ya han salido de sus barrios de origen, no sólo para alcanzar territorios periféricos (como determinados barrios adyacentes), sino llegando a lugares como el

\footnotetext{
${ }^{3}$ Organismo supra-asociativo que coordina e integra a las hermandades que organizan el ritual. Tiene capacidad para sancionar la ortodoxia festiva.
} 
Centro Penitenciario de Picassent, cerca de Valencia, o localidades más alejadas, a las que las cofradías se acercan como invitadas para salir en procesión acompañando a las cofradías locales ${ }^{4}$. Más compleja es, sin embargo, la relación con el centro de Valencia, desde cuyo arzobispado se está intentando relanzar las procesiones por el casco antiguo de la ciudad, lo que está generando debates sobre dónde deberían transcurrir los actos más importantes (especialmente en Viernes Santo): los viejos Poblados Marítimos no parecen dispuestos a sacrificar una primacía ganada a través de muchos años; por otra parte, los intentos de algunas - pocas- cofradías de la Semana Santa Marinera de promocionarse acudiendo al centro de la ciudad los Viernes de Dolores no han obtenido demasiada aceptación, ni siquiera entre sus propios cofrades. Y es especialmente significativa, como indicador de una fuerte identidad territorial, esta reticencia a desfilar por el centro de la ciudad por parte de unas cofradías que no tienen ningún problema en acudir como invitadas a procesiones de localidades más o menos cercanas, como Silla, Sagunt o Calahorra, por poner algunos ejemplos.

\section{Identidad mediática}

El proceso de desterritorialización y reterritorialización, característico de la modernidad globalizada, somete al ritual a nuevas resemantizaciones, que crean a su vez nuevos niveles de identidad. Estos son más problemáticos de definir, por lo que deberemos detenernos en ellos de manera más extensa.

Durante los últimos años, la presencia de la fiesta en los medios de comunicación ha aumentado de manera importante. Empezaron creciendo sus apariciones en la prensa, que contribuye a la difusión de sus actos a través de suplementos monográficos — aparte del seguimiento diario de los actos de calle y actividades de las cofradías-. Este aumento tiene su correlación en un mayor eco en los medios audiovisuales: las televisiones autonómicas han retransmitido en los últimos años algunos de sus festejos más significativos, como el Santo Entierro o el Desfile de Resurrección, que son radiados también por algunas emisoras locales. No sólo en los días de Semana Santa: determinadas cadenas televisivas locales informan con relativa asiduidad de las actividades del mundo cofradiero a lo largo de todo el año. Junto a los canales clásicos, la fiesta se promociona también utilizando las nuevas tecnologías de comunicación audiovisual y, especialmente, aumen-

\footnotetext{
${ }^{4}$ Puede verse a la Cofradía de Jesús en la Columna desfilando por el interior del recinto carcelario en Levante-EMV, 1-IV-1999, p. 33. Incluso los telediarios de ámbito estatal suelen ofrecer anualmente imágenes de esta singular procesión cuando llegan los días pertinentes.
} 
tando su presencia en Internet, lo que permite participar de las celebraciones no sólo alejándose en el espacio, sino incluso en el tiempo.

Este interés mutuo entre los medios de comunicación y los agentes organizadores de la fiesta tiene sus repercusiones sobre la ejecución del ritual. En primer lugar, el medio actúa como un instrumento de control, pues la brillantez del mismo podrá realzar la fiesta, pero ninguno de sus protagonistas actuará igual sabiendo que la cámara de televisión lo mira. Además, el ojo televisivo selecciona necesariamente determinados festejos, lo que trae a su vez modificaciones en la secuencia ritual, creándose así un efecto de bola de nieve, pues se acude más a los actos más publicitados. Y no hay que perder de vista que, en determinados momentos, son los ya aludidos políticos quienes atraen a los medios.

Podría argüirse al respecto que la mirada televisiva es esencialmente profana, en oposición a las definiciones clásicas del rito, según las cuales éste se caracterizaría por la búsqueda de la fusión sagrada (González Requena 1992: 58-59). No muy lejos de esta opinión se encuentra Franco Ferrarotti, para quien, "el medio televisivo destruye cualquier rito", ya que a través del mismo, la comunidad de fieles desaparece "en lo indistinto del indiferenciado público de los telespectadores” (1991: 99). En estas condiciones, se produciría un enfriamiento del carisma, que se volvería previsible y banal (Ferrarotti 1991: 96-100).

Aun teniendo en cuenta que el objetivo de los comentarios de Ferrarotti no eran los rituales festivos, sino analizar el caso de Juan Pablo II como "Papa televisivo", no parece que la evolución reciente de los fenómenos religiosos venga a dar por buenos sus planteamientos. Antes que enfriar el carisma, parece que los mass media pueden obrar como ritos comunicativos: "la esencia profunda de los medios de comunicación sólo puede ser captada en el horizonte ritual desde el que se constituye toda sociedad", ha afirmado recientemente Bericat Alastuey (2002: 766), cuya postura viene a coincidir con las advertencias realizadas recientemente desde la antropología, en el sentido de que los medios modernos de comunicación "funcionan a modo de creaciones rituales de la modernidad" (Segalen 2005: 22).

En la misma línea, había indicado con anterioridad Gonzalo Abril que "hay buenas razones para considerar gran parte de las operaciones de la cultura de masas como procesos rituales" (1997: 163). Según esta visión, nos encontraríamos ante una nueva forma de ritualismo, en la que "la participación directa de los ritos tradicionales se ha visto sustituida por una participación vicaria" (Abril 1997: 163). No se alejan mucho estas observaciones de las realizadas por Antonio Ariño por las mismas fechas:

[...] la centralidad de la experiencia mediada, fenómeno radicalmente moderno, constituye un poderoso factor de creación de sujetos celebrantes. Por ello, pode- 
mos hablar de sujetos (y comunidades) mediáticos, para referirnos primariamente, no al espectador que de modo casual e imprevisto ve en su televisor las imágenes seductoras de un ritual que desconocía, sino a aquellos segmentos de la audiencia que seleccionan voluntariamente la recepción de programas festivos y que lo hacen para vibrar vicariamente y experimentar una comunión imaginaria con fiestas que de este modo adquieren significado universal, o al menos, de representación étnica (Ariño Villarroya 1996: 15).

Así, la participación directa en los rituales tradicionales se ve reemplazada —o mejor, acompañada, simultáneamente o no-, "por una participación escópica, espectacularizada" (Abril 1997: 165). Ya se ha apuntado que en la fiesta "cada individuo decide su forma de inserción y su grado de implicación" (Ariño Villarroya 1996: 15); de manera que el público de la misma - actores y espectadores- se nutre tanto de los vecinos del barrio como de los que ya no residen en él pero son pendularmente atraídos por el ritual, los curiosos, turistas o, en último término, de todo aquel que quiera sintonizar con la fiesta a través de los medios de comunicación. Asistimos, pues a nuevas formas de agregación: de las asociaciones voluntarias especializadas que son las cofradías a la congregación más o menos casual de espectadores, y de éstos a las audiencias televisivas. El ritual adquiere así un carácter mixto: es al mismo tiempo territorial y mediático (Bericat Alastuey 2002: 772-775). Desde esta perspectiva, una procesión es susceptible de actuar, en términos funcionales, exactamente igual que, por ejemplo, un partido de fútbol: en ningún caso la emoción colectiva desaparece con el medio, pues, "si la comunicación es la esencia del rito, este cambio del espacio territorial al espacio mediático no altera en absoluto su eficacia" (Id. 2002: 779). No en vano, Howard Rheinhold habla de la "adhesión emocional a un ritual tecnológico aparentemente insensible" como una característica de sus "comunidades virtuales" (Rheinhold 1996: 15).

En el mundo de la "religión a la carta" (Moncada 1996), cada cual decide su forma de inserción y su grado de implicación. Vale aquí la advertencia de Giddens (1994), para quien el sujeto moderno se ve forzado a elegir constantemente, inventándose así una identidad de manera refleja. Cualquier conceptualización de la modernidad globalizada o avanzada implica la movilidad continua, tanto desde el punto de vista de la movilidad social y geográfica como desde los esquemas cognitivos del individuo (Berger y Luckman 1997). La acción ritual, incluso en el caso del más tradicional ritual público del catolicismo, permite así la creación de comunidades escópicas, en las que la comunidad local deja de constituir un sistema claramente delimitado. Como se ha dicho en otro lugar: "La comunidad local no existe ya como sujeto circunscrito de la fiesta más que en un plano político (en tanto que hay un poder representativo y responsable) e imaginario (en tanto que en 
las mentes participantes existe una cierta idea de comunión)" (Ariño Villarroya 1996: 15).

La emergencia de formas de comunicación - y de conocimiento- desterritorializadas tiene pues una consecuencia fundamental: frente al modelo clásico de comunidad celebrante del ritual, podemos hablar ahora de la progresiva formación de una comunidad "virtual", "imaginaria" (Abril 1997), o —quizá mejor- de comunidades escópicas, dispersas y desterritorializadas. La televisión —o, en menor medida, la prensa, el CD-Rom o Internet- propiciaría así un nivel de identificación imaginaria que se caracterizaría por la ambigüedad:

Como tantas otras expresiones de la cultura contemporánea, ésta es inevitablemente ambigua: en la identificación imaginaria propiciada por la televisión la diferencia social a la vez se expresa y se encubre; en ella la nostalgia de la comunidad y de los modos de convivencia tradicionales coexisten con la reidentificación en una imprecisa modernidad transnacional (Abril 1997: 56).

Sabemos, gracias a estudios seminales como los de Victor Turner (1997), que los símbolos rituales son flexibles, y pueden contener significados múltiples, haciéndose con ello susceptibles de continuas y diversas manipulaciones. Con mayor razón, en el caso del ritual mediático, los significados ya no se basarán — si es que alguna vez lo hicieron completamente- en robustos sistemas simbólicos compartidos socialmente, sino que son restituidos por "pactos contingentes de lectura" (Abril 1997: 165). Serán pues múltiples y recombinables los efectos y las adhesiones que pueda causar la visualización, a través de distintos medios, de una imagen pasional o una procesión en el complejo marco social contemporáneo, en el que actúan grupos sociales sumamente heterogéneos, que no participan del mismo corpus de tradiciones, y que se hallan "continuamente involucrados en tanteos y negociaciones” (García García y otros 1991: 12). El carácter performativo del ritual actúa así creando unos niveles de identidad mucho más amplios y multiformes que los anteriormente expuestos. Teniendo en cuenta, sin embargo, que tales niveles no tienen por qué, necesariamente, acabar con aquéllos, más bien será el momento, el lugar o la propia correlación de fuerzas de los actores lo que, en ese campo de significados que configura el ritual festivo, conceda momentánea o alternativamente la primacía a uno $\mathrm{u}$ otro nivel.

Vemos, pues, que John B. Thompson (1996) tiene razón cuando afirma que los mass media son capaces de reconstruir la tradición, aunque ésta se despersonalice y se desarraigue de lugares concretos, volviéndose independiente de las formas de interacción locales o "cara a cara". No la tiene, sin embargo, cuando afirma que contribuyen a fijar su contenido simbólico, ni 
mucho menos cuando dice que la tradición se ha desritualizado, tal como afirma sorpresivamente, pese a que él mismo aporta datos que demuestran lo contrario.

Por otra parte, también se debe tener en cuenta que, en tanto los medios de comunicación tienden a establecer, en gran medida, el régimen de visibilidad y reconocimiento público de las identidades colectivas (Sampedro Blanco 2004), la lucha por aumentar su presencia en los medios forma parte de la lucha por el reconocimiento entendida, al modo de Honneth (1997), como respuesta a una subjetividad herida. Desde una identidad históricamente marginada, como es el caso de estos barrios (Boira Maiques 1987; Boira Maiques y Serra Désfilis 1994), se busca conseguir una identidad normalizada a través de la difusión de la tradición. Y en condiciones de modernidad globalizada, ésta sólo puede se puede construir como identidad mediática. A cambio, el ritual debe renunciar, en mayor o menor medida, a apoyarse exclusivamente en un territorio local bien definido.

Rituales translocales: la Semana Santa Marinera en el universo festivo de la Semana Santa

Los distintos niveles de identidad expuestos hasta el momento tienen una base común: en todos los casos la Semana Santa Marinera es el ritual, el dispositivo que, sea compitiendo, sea complementándose, activa distintos significados o niveles identitarios en su seno. Ahora bien, los procesos de recomposición territorial que caracterizan a la modernidad globalizada son susceptibles de incluir al ritual dentro de redes en las que la Semana Santa Marinera ya no es el centro, sino un punto más dentro del universo festivo común de la Semana Santa. Por otra parte, no sólo se desborda el espacio: a través de estas nuevas prácticas emergentes, el tiempo de la Semana Santa es susceptible de extenderse en el tiempo a lo largo de todo el año. Se activan así nuevas formas de identidad, unas más incipientes que otras, pero en todo caso construidas de manera transversal, híbrida, descentrada y sobre una base territorial cada vez menos definida.

\section{La Junta Diocesana de Hermandades de Semana Santa}

La Semana Santa Marinera de Valencia ingresa en la Junta Diocesana de Hermandades de Semana Santa en el año 2002, integrándose así dentro de una red que ha ido incrementándose sin cesar desde 1975, hasta albergar en la actualidad a más de treinta localidades. En principio, esto supone la aceptación de la jurisdicción del arzobispado sobre cualquier tema que afecte 
a las celebraciones, tanto durante la Semana Santa como durante el resto del año. En la práctica, el principal efecto de tal integración ha sido la emergencia de un ámbito identitario nuevo, basado en la existencia de prácticas comunes dentro de un territorio limitado según el derecho canónico. Debe destacarse que este nuevo nivel de identidad encuentra su máxima expresión en una magna procesión anual (la "Procesión Diocesana"), que se viene realizando desde el año 1986, a la que acuden representaciones de todas las cofradías adscritas a la Junta Diocesana. Ahora bien, la gran paradoja que supone la consolidación de este nivel de identidad es que, no pudiendo realizar su procesión durante la Semana Santa (y ahí se ve claramente cómo las identidades locales siguen primando), suele llevarse a cabo durante el mes de febrero, es decir, en pleno período carnavalesco.

En todo caso, el hecho de que se perciba la necesidad de un organismo que coordine a los cientos de cofradías pasionistas que salen a la calle en el territorio de la Diócesis de Valencia durante la Semana Santa, indica claramente el surgimiento de un nivel de identidad nuevo, de carácter decididamente supralocal. Aún así, la base territorial del mismo sigue estando claramente delimitada por la jurisdicción eclesiástica. Mayores son las extensiones territoriales que se tratan a continuación.

\section{Encuentros estatales}

Más allá de la agrupación constituida por las diversas juntas de hermandades pertenecientes a la diócesis valenciana, encontramos ya plenamente consolidados otros niveles de identidad, cuya base territorial se amplía hasta alcanzar el ámbito estatal, como es el caso de los encuentros anuales que cada año se celebran en una población distinta (el primer encuentro fue en Zamora, en 1987). Éstos actúan como una especie de feria de muestras de Semana Santa a nivel nacional, y de ellos se valora de manera especial el darse a conocer a otras localidades, pero también el aprender de ellas, así como la posibilidad de establecer nuevas relaciones de sociabilidad.

Pero si tales encuentros estatales son susceptibles de articular círculos de identidad progresivamente inclusivos (de la cofradía de barrio a la totalidad de semanas santas del Estado), un segundo tipo de encuentros contribuyen a la construcción de niveles de identidad aún más transversales: son los derivados de la devoción a un determinado paso o misterio de la Pasión, que sirven para reunir con cierta periodicidad a cofradías de ámbito autonómico o estatal, cuyo denominador común es compartir una advocación similar: tenemos así, desde hace varios años, encuentros nacionales de cofradías de Jesús de Medinaceli, de la Vera Cruz, de la Oración en el Huer- 
to, del Segundo Misterio Doloroso, o de la Última Cena, por citar algunos de entre los múltiples ejemplos posibles. Aunque, en el caso de los encuentros (generales o transversales) no se haya llegado, como en el caso de la Junta Diocesana, a realizar procesiones penitenciales fuera del tiempo establecido para las mismas, el nivel de formalización y ritualización alcanzado por estos eventos es sumamente elevado, como muestra su periodicidad y preparación anual, pudiendo afirmarse al respecto que la propia celebración del encuentro es el ritual destinado a activar ese nivel de identidad, que se ve mantenido a lo largo del año por pequeños rituales de sociabilidad de menor visibilidad mediática (visitas puntuales entre cofrades de distintas localidades, comunicación mediada electrónicamente, etc.).

\section{Devociones en red e identidades virtuales}

Desde la misma perspectiva son susceptibles de ser interpretadas prácticas que invaden el calendario a lo largo de todo el año, desde la común referencia cultural de una ahora ya no claramente territorializada Semana Santa. Si bien la sociabilidad cofrade tiende a densificar las interacciones entre muchos de sus miembros a lo largo de todo el año a una escala local, las nuevas tecnologías de la comunicación permiten la emergencia de nuevas formas de sociabilidad, de base territorial mucho más incierta. Así, vemos por ejemplo proliferar foros de temática cofrade en Internet, que se convierte en un nuevo lugar de intercambio de experiencias y conocimiento de prácticas alejadas en el espacio. De manera explícita, lo que emerge aquí es lo que Brisset (2001) denomina un "universo festivo": el universo de devotos y aficionados a la Semana Santa, que se convierte en comunidad virtual gracias a los mecanismos de conectividad compleja que caracterizan desde el punto cultural a la globalización (Tomlinson 2001). El objetivo común de realizar procesiones en sus respectivos lugares durante los mismos días sirve como base para la percepción de unos intereses comunes: al fin y al cabo, como a lo largo del trabajo de campo me manifestó un informante, "todos estamos trabajando para lo mismo".

La complejidad y los múltiples matices de estas interacciones requieren pues estudiar las identidades como procesos de negociación, ya que incorporan hibridación y ductilidad sobre lo local, sin perder de vista nunca las condiciones sociohistóricas de éste, no reductibles a una mera puesta en escena. Como afirma García Canclini, "la identidad es teatro y es política, es actuación y acción" (1995: 132). Por otra parte, y tanto en este caso como en el de las identidades mediáticas, la proliferación de estas prácticas coadyuva todavía más a fortalecer el proceso de secularización, pues esca- 
pan por completo al ámbito de implantación local, que queda como único espacio de actuación para la parroquia. Utilizando la metáfora de David Lyon (1987), no sólo es que la sombra del campanario ya no albergue a muchos de los que viven en torno a éste; es que nos encontramos ante espacios a los que tal sombra nunca ha llegado.

\section{CONCLUSIONES}

Una pequeña fiesta de tres barrios de la ciudad de la ciudad de Valencia, asentada originariamente sobre una fuerte identidad local, nos muestra que nos encontramos en realidad ante una red polimórfica de procesiones, o de otras modalidades de interacciones, cara a cara o de manera virtual, que se superponen unas a otras, que en ocasiones compiten y en otras se complementan. Como sucede con los mundos de la vida (Berger y Luckmann 1997), cualquier pretensión de totalidad se ve, también en el caso del ritual festivo tradicional, arrastrada en un torbellino cada vez más complejo y entremezclado de horizontes de entendimiento.

La equidad inequívoca entre los espacios físico, social y ritual que propugnan determinados estudios (ver por ejemplo Provansal y Molina 1989) se ve así decididamente superada. El caso analizado demuestra que tampoco son válidas ya, al menos para todos los casos, interpretaciones como la de un antropólogo que, al analizar los recorridos procesionales de una localidad valenciana, afirmó hace unos años que, mediante los mismos, la comunidad local, puesta en marcha, "afirma en dicha ordenación el ideal de su unidad" (Sanmartín 1993: 104), ni seguir insistiendo exclusivamente en que los recorridos procesionales hacen revivir a la comunidad su pasado, como se ha dicho a propósito de la Semana Santa de Zamora (Úbeda de Mingo 1993).

Definitivamente, y como ya viese Abbruzzese (1999), la secularización replantea la relación entre religión y territorio, lo que se refleja en un ritual tradicional como el de la Semana Santa que, heredado del pasado, ha visto radicalmente alteradas sus funciones y sus significados durante la modernidad. También debemos plantearnos dónde queda esa verdad formulaica que Giddens (1997) caracteriza como uno de los atributos constitutivos de la tradición, una tradición que avanza ahora definitivamente desligada de una hierocracia de guardianes cada vez más aislados en sus bien delimitadas parroquias. Pues si, como afirmara Halbwachs (1971: 124), para afirmarse en la memoria de un grupo, una verdad debía asentarse en la materialidad de un lugar, podemos preguntarnos dónde queda la verdad de estos grupos cada vez más indeterminados. 
Cuando, como hemos visto, el ritual se descentra, lo que refleja y a la vez sanciona es el profundo descentramiento de las sociedades de la modernidad avanzada. Resulta entonces lógico pensar que, como señala Habermas, "incluso las identidades colectivas están sometidas a esta clase de oscilación en el flujo de las interpretaciones y se ajustan más a la imagen de una red frágil que a la de un centro estable de autorreflexión" (Habermas 1989: 424). En la misma dirección, Juan Carlos Alútiz señala que asistimos a la sustitución de las directrices provenientes de una identidad fuerte convencional por las identidades frágiles de la postmodernidad:

[...] así, la identidad ya no se va a sostener en estructuras normativas de carácter simbólico prescriptivas para toda una sociedad (y respaldadas fácticamente desde un orden social 'tradicional'), sino que se va a fragmentar en una multiplicidad de opciones de valor sobre las que el individuo tiene la necesidad de elegir para definirse a sí mismo y su lugar en el mundo (Alútiz 2004: 38).

Por esto las identidades que el ritual construye $-\mathrm{y}$ no sólo reproduceestán sufriendo cambios de fondo. Las identidades establecidas ceden paso a procesos de identificación de los sujetos: no falta al respecto quien ha hablado de la "destrucción creadora" de las identidades (Fortuna 1998). La expresión es, como mínimo, discutible (las nuevas formas de identidad que crea el ritual no destruyen necesariamente a las anteriores que, como hemos visto, pueden seguir manteniendo la primacía), pero parece claro que, como advierte el mismo autor, al descentrarse los sujetos, éstas se problematizan. Las sólidas localizaciones que, como grupos y como individuos, antaño nos proporcionaba el ritual, se desestabilizan en la modernidad avanzada o globalizada, pues la multiplicación de referentes a los que se enfrenta el sujeto provocan no sólo un descentramiento de la sociedad, "sino también de los individuos, que ahora viven una integración parcial y precaria de las múltiples dimensiones que los conforman" (Martín-Barbero 2002: 59). Procesiones de cofradía, de parroquia, de barrio, de tres barrios, de una o varias poblaciones, encuentros nacionales o foros virtuales en Internet: ni siquiera en su calidad de cofrade el individuo es indivisible, y cualquier unidad que postule tendrá, parafraseando a Benedict Anderson (2005), mucho de imaginada. Debe insistirse en que esto no significa, ni mucho menos, que no se construyan procesos de identificación que asuman frecuentemente una condición prioritaria. Antes bien, y como ha señalado Sousa Santos:

La identidad es siempre un paso transitorio en un proceso de identificación. Los grupos sociales y los individuos acumulan, a lo largo del tiempo, diferentes identidades y en cada momento pueden disponer de varias identidades complementarias o contradictorias. De este stock identitario, una de las identidades asume, según las circunstancias, la primacía, y en consecuencia el análisis de este proceso es de gran importancia para comprender la política que entrará a protagonizar o a respaldar tal identidad (Santos 2005: 224). 
Los "contactos continuos en el espacio y en el tiempo" que Mannheim llamaba a analizar ya no son, en definitiva, la base de la reproducción de una tradición transmitida intergeneracionalmente (Shils 1975), pues la tradición ya no es una mera herencia ni un anclaje en el pasado: se construye en el uso que los agentes, libremente adheridos, quieran hacer de ella. En la fase globalizada de la modernidad, pues, el más tradicional de los rituales del catolicismo es susceptible de suscitar, incluso en unos pequeños barrios de la fachada marítima de la ciudad de Valencia, niveles de identidad en permanente proceso de negociación, fluctuando sobre territorios cada vez más inciertos. Esto refuerza el proceso de secularización de un ritual que, al complejizar su sujeto celebrante, ha perdido definitivamente la antigua y exclusiva centralidad del objeto celebrado. Un ritual, en definitiva, tan descentrado y politeísta como la sociedad que lo produce.

\section{BIBLIOGRAFÍA CITADA}

Abbruzzese, S. 1999. "Catholicisme et territoire: pour une entrée en matière". Archives des Sciences Sociales des Religions 107, 1: 5-19.

Abril, G. 1997. Teoría general de la información. Datos, relatos y ritos. Madrid: Cátedra.

Alútiz, J.C. 2004. "Los estadios morales de la evolución social". Papers. Revista de Sociologia 74: 11-44.

Anderson, B. 2005. Comunitats imaginades. Reflexions sobre l'origen i la propagació del nacionalisme. València: Universitat de València.

Ariño Villarroya, A. 1992. La ciudad ritual. La fiesta de las Fallas. Barcelona: Anthropos.

Ariño Villarroya, A. 1996. "La utopía de Dionisos. Sobre las transformaciones de la fiesta en la modernidad avanzada". Antropología. Revista de pensamiento antropológico y estudios etnográficos 11: 5-19.

Baumann, G. 1992. "Ritual implicates 'Others': Reading Durkheim in a plural Society", en D. de Coppet (ed.), Understanding Rituals: 97-115. Londres: Routledge.

Beck, U. 1998. La sociedad del riesgo. Hacia una nueva modernidad. Barcelona: Paidós.

Berger, P. L. y Th. Luckmann. 1997. Modernidad, pluralismo y crisis de sentido. La orientación del hombre moderno. Barcelona: Paidós.

Beriain, J. 2000. La lucha de los dioses en la modernidad. Del monoteísmo religioso al politeísmo cultural. Barcelona: Anthropos.

Bericat Alastuey, E. 2002. "Rituales mediáticos, emociones colectivas y orden social", en Varios Autores., La sociedad. Teoría e investigación empírica. Estudios en honor a José Jiménez Blanco: 765-782. Madrid: CIS.

Boira Maiques, J. V. 1987. El Cabanyal-Canyamelar. Valencia: Ayuntamiento de Valencia.

Boira Maiques, J. V. y A. Serra Désfilis. 1994. El Grau de València. La construcció d'un espai urbà. Valencia: Institució Valencia d'Estudis i Investigació.

Boissevain, J. (ed.) 1992. Revitalizing European Rituals. Londres: Routledge.

Bourdieu, P. 2001. El campo político. La Paz: Plural Editores.

Brisset, D. E. 2001. "Fiestas hispanas de moros y cristianos. Historia y significados". Gazeta de Antropologia 17. <http://www.ugr.es/ pwlac/G17_03DemetrioE_Brisset_Martin.html> Consultada 26/03/2005. 
Checa, F. 1992. "La Semana Santa de Motril, vista desde la antropología", en P. Gómez García (ed.), Fiestas y religión en la cultura popular andaluza: 83-106. Granada: Universidad.

Cruces Villalobos, F. 2004. "Procesos formativos en la expresividad urbana: tradición, instrumentalidad, autocensura, transgresión y comunicación crítica”, en C. Ortiz (ed.), La ciudad es para ti. Nuevas y viejas tradiciones en ámbitos urbanos: 19-36. Barcelona: Anthropos.

Delgado, M. 1992. La festa a Catalunya, avui. Barcelona: Barcanova.

Durkheim, E. 1982. Las formas elementales de la vida religiosa. Madrid: Akal.

Evans-Pritchard, E. E. 1992. Los nuer. Barcelona: Anagrama.

Ferrarotti, F. 1991. La bistoria y lo cotidiano. Barcelona: Península.

Fortuna, C. 1998. "Las ciudades y las identidades: patrimonios, memorias y narrativas sociales". Alteridades 16: 61-74.

Fustel de Coulanges, N. D. 1984. La ciudad antigua. Barcelona: Península.

García Canclini, N. 1995. Consumidores y ciudadanos. Conflictos multiculturales de la globalización. México: Grijalbo.

García García, J. L. y otros. 1991. Rituales y proceso social. Estudio comparativo en cinco zonas españolas. Madrid: Ministerio de Cultura.

García Pilán, P. 2002. "Al calor y colorido de nuestras procesiones'. La voluntat turística de la Setmana Santa Marinera de València”. Caramella. Revista de Música i Cultura Popular VII: 25-30.

García Pilán, P. 2010. Tradición en la modernidad avanzada: la Semana Santa Marinera de Valencia. Valencia: Museu Valencià d'Etnologia.

Giddens, A. 1994. Modernidad e identidad del yo. El yo y la sociedad en la época contemporánea. Barcelona: Península.

Giddens, A. 1997. "Vivir en una sociedad postradicional", en U. Beck; A. Giddens y S. Lash, Modernización reflexiva. Política, tradición y estética en el orden social moderno: 75-136. Madrid: Alianza.

Gil Calvo, E. 1996. "La disolución festiva". Antropología. Revista de pensamiento antropológico y estudios etnográficos 11: 135-145.

Giner, S. 2003. Carisma y razón. La estructura moral de la sociedad moderna. Madrid: Alianza.

González Alcantud, J. A. 1993. "Territorio y ruido en la fiesta", en Agresión y rito y otros ensayos de antropología andaluza: 13-41. Granada: Diputación Provincial de Granada.

González Requena, J. 1992. El discurso televisivo: espectáculo de la posmodernidad. Madrid: Cátedra.

Habermas, J. 1989. El discurso filosófico de la modernidad. Madrid: Taurus.

Halbwachs, M. 1971. La topographie légendaire des Évangelies en Terre Sainte. París: PUF.

Hall, S. 2003. "Introducción: ¿quién necesita 'identidad'?", en S. Hall y P. du Gay (comps.), Cuestiones de identidad cultural: 13-39. Buenos Aires: Amorrortu.

Heelas, P.; S. Lash y P. Morris (eds.) 1996. Detraditionalization. Critical Reflections on Authority and Identity. Oxford: Blackwell Publishers.

Homobono, J. I. 2004. "Fiesta, ritual y símbolo: epifanías de las identidades". Zainak. Cuadernos de Antropología - Etnografía 26: 33-76.

Honneth, A. 1997. La lucha por el reconocimiento. Por una gramática moral de los conflictos sociales. Barcelona: Crítica.

Jimeno Salvatierra, P. 2002. Rituales de identidad revitalizados. Madrid: Universidad Autónoma de Madrid.

Lyon, D. 1987. The Steeple's Shadow: On the Myths and Realities of Secularization. Londres: SPCK. 
Mannheim, K. 1962. Ensayos de sociología de la cultura. Madrid: Aguilar.

Martín-Barbero, J. 2002. "Desencuentros de la socialidad y reencantamientos de la identidad". Anàlisi. Quaderns de comunicació i cultura 29: 45-62.

Merton, R. K. 1995. Teoría y estructura sociales. México: FCE.

Moncada, A. 1996. Religión a la carta. Madrid: Espasa Calpe.

Moreno Navarro, I. 1972. Propiedad, clases sociales y hermandades en la Baja Andalucía. La estructura social de un pueblo del Aljarafe. Madrid: Siglo XXI.

Moreno Navarro, I. 1990a. "Niveles de significación de los iconos religiosos y rituales de reproducción de identidad en Andalucía", en P. Córdoba y J.-P. Étienvre (comps.), La fiesta, la ceremonia, el rito: 91-103. Granada: Casa de Velázquez - Universidad de Granada.

Moreno Navarro, I. 1990b. "Rituales colectivos de religiosidad popular y reproducción de identidades de Andalucía”, en J. Cucó y J. J. Pujadas (coords.), Identidades colectivas. Etnicidad y sociabilidad en la Península Ibérica: 269-284. València: Generalitat Valenciana.

Ortiz, R. 1996. "Otro territorio". Antropología. Revista de pensamiento antropológico y estudios etnográficos 12: 5-21.

Pitt-Rivers, J. 1986. "L'identité locale vue à travers la 'fiesta'", en Y.-R. Fonquerne y A. Esteban (coords.), Culturas populares. Diferencias, divergencias, conflictos: 11-23. Madrid: Casa de Velázquez.

Provansal, D. y P. Molina. 1989. "Rituales religiosos y tensiones sociales en Andalucía oriental”, en C. Álvarez Santaló, Mํㅗ. J. Buxó y S. Rodríguez Becerra (coords.), La religiosidad popular, III: Hermandades, romerias y santuarios: 449-457. Barcelona: Anthropos.

Rheingold, H. 1996. La comunidad virtual. Barcelona: Gedisa.

Sanmartín, R. 1993. Identidad y creación. Horizontes culturales e interpretación antropológica. Barcelona: Humanidades.

Sampedro Blanco, V. F. 2004. "Identidades mediáticas e identificaciones mediatizadas. Visibilidad y reconocimiento identitario en los medios de comunicación". Revista CIDOB d'Afers Internacionals 66-67: 135-149.

Santos, B. de S. 2005. El milenio huérfano. Ensayos para una nueva cultura política. Madrid: Trotta.

Segalen, M. 2005. Ritos y rituales contemporáneos. Madrid: Alianza.

Shils, E. 1975. "Tradition", en Center and Periphery. Essays in Macrosociology: 183-218. Chicago-Londres: The University of Chicago Press.

Thompson, J. B. 1996. "Tradition and Self in a Mediated World", en P. Heelas, S. Lash y P. Morris (eds.), Detraditionalization. Critical Reflections on Authority and Identity: 89-108. Oxford: Blackwell Publishers.

Tomlinson, J. 2001. Globalización y cultura. México: Oxford University Press.

Turner, V. 1997. La selva de los símbolos. Madrid: Siglo XXI.

Úbeda de Mingo, P. 1993. "Ritualización y espacio: la Semana Santa zamorana", en J. C. Lisón Arcal (ed.), Espacio y cultura: 71-90. Madrid: Coloquio. 